\title{
Relationship between study habits and academic achievement in students of medical sciences in Kermanshah-Iran
}

This article was published in the following Dove Press journal:

Advances in Medical Education and Practice

Haleh Jafari ${ }^{1}$

Abbas Aghaei ${ }^{2}$

Alireza Khatony $\left(\mathbb{D}^{3}\right.$

'Clinical Research Development Center of Imam Reza Hospital, Kermanshah University of Medical Sciences, Kermanshah, Iran; ${ }^{2}$ Social Determinants of Health Research Center, Research Institute for Health Development, Kurdistan University of Medical Sciences, Sanandaj, Iran; ${ }^{3}$ Health Institute, Social Development and Health Promotion Research Center, Kermanshah University of Medical Sciences, Kermanshah, Iran

Correspondence: Alireza Khatony Clinical Research Development Center, Imam Reza Hospital, Nurse Blvd., Kermanshah, Iran

Tel +98 8338279394

Fax +988338279394

Email Akhatony@gmail.com
Purpose: Study habits have been the most important predictor of academic performance and play a special role in the academic achievement of students. The aim of this study was to investigate the status of study habits and its relationship with academic achievement in medical sciences students in Kermanshah-Iran.

Materials and methods: This cross-sectional study was carried out on 380 medical sciences students at Kermanshah University of Medical Sciences. The samples were randomly assigned to the study. The Palsane and Sharma study Habit Inventory was the tool used for data collection. Data were analyzed by descriptive and inferential statistics.

Results: The mean of students' grade point average was $15.73 \pm 1.5$ out of 20 and the mean of total status of study habits was $45.70 \pm 11.36$ out of 90 . The status of study habits in $81.3 \%$ of the students was at moderate level. There was a direct and significant relationship between study habits and academic achievement.

Conclusion: The status of study habits was at moderate level for most students. Therefore, it is recommended to consider and assess students' study habits at the time of entry into university, in addition, specific training should be offered to students in order to help them learn or modify study habits to increase their academic achievements.

Keywords: academic achievement, student, study habit

\section{Introduction}

Academic performance of students is one of the main indicators used to evaluate the quality of education in universities. ${ }^{1,2}$ Academic performance is a complex process that is influenced by several factors, such as study habits. ${ }^{2}$ Study habit is different individual behavior in relation to studying ${ }^{3}$ and is a combination of study method and skill. ${ }^{4}$ In other words, study habits include behaviors and skills that can increase motivation and convert the study into an effective process with high returns, which ultimately increases the learning. ${ }^{5}$ This skill is also defined as any activity that facilitates the process of learning about a topic, solving the problems or memorizing part or all of the presented materials. ${ }^{3}$ Study habits are in fact the gateway to success and differ from person to person. ${ }^{4}$

According to previous studies, good study habits include studying in a quite place, studying daily, turning off devices that interfere with study (such as TV and mobile phones), taking notes of important content, having regular rests and breaks, listening to soft music, studying based on own learning style, and prioritizing the 
difficult contents. ${ }^{6}$ Some of the worst study habits include procrastination, evading the study, studying in inappropriate conditions, and loud sound of music and television during studying. ${ }^{7}$

Study habits are the most important predictor of academic performance and global research has revealed that study habits affect academic performance. ${ }^{8}$ In this regard, medical students are faced with a large amount of information that is difficult to organize and learn, and requires knowledge and application of study skills. ${ }^{5,9}$ Evidence suggests that learners who do not have enough information about study strategies do not attain effective and stable learning, and therefore will not have an appropriate level of academic achievement. ${ }^{3}$ In other words, students with better academic achievement use these skills more than those with lower academic achievement. ${ }^{10}$

Given the important role of study skills in a student's academic achievement, today, many prestigious universities such as York University in Canada and University of Berkeley in California teach study skills to newly-enrolled students. ${ }^{11}$ In different studies, study skills and habits and their relationship with students' academic achievement have been studied and different results have been reported. ${ }^{1,3,12}$ Also, various studies have reported the study habits of students from weak to desirable levels. ${ }^{5,7,10}$ In this regard, a study conducted on study habits of students in 21 medical universities in Iran showed that $32 \%$ of the students suffered from a severe lack of study skills and habits. ${ }^{10}$ In many studies, a positive and significant correlation has been found between students' study habits and their academic achievement. ${ }^{4,6,7,10}$ However, in Lawrence's study, no significant relationship was found between these two variables. ${ }^{1}$

Considering the importance of study skills and habits of students, and the important role they play in the academic achievement of students, and taking into account that study habits vary from person to person and from place to place, and also as the results of related studies are different from each other, the present study was designed and implemented. Our goal was to investigate the relationship between study habits and academic achievement of medical sciences students in Kermanshah University of Medical Sciences (KUMS), Iran.

\section{Methods}

\section{Study design}

The present study had a descriptive-analytical and crosssectional design and was conducted between November 2017 and April 2018.

\section{Study questions}

We sought to answer the following questions: 1) what is the status of students' study habits in terms of variables such as; faculty, place of study, academic degree, history of probation, status of residence, and gender? 2) what is the status of students' academic achievement in terms of variables such as; faculty, place of study, academic degree, history of probation, status of residence, and gender? and 3) what is the relationship between the status of study habits and students' academic achievement?

\section{Sample and sampling method}

PASS/11 software was used to calculate the sample size. For this purpose, according to the results of Nourian et al's study (2011), in which the highest standard error rate was $0.96,{ }^{11}$ the minimum sample size was calculated to be 328 individuals with the first type error of 0.05 , and the accuracy limitation of estimated mean of 1 unit. Considering the $15 \%$ probability of not responding, 380 students were enrolled in the study. The samples were selected randomly from different faculties of KUMS, which included the faculties of medicine, nursing and midwifery, dentistry, paramedicine, pharmacology, and health. The sampling classes were formed by the faculties of the university. In each class, proportional to the size of students, numbers of samples were selected randomly using a random table of numbers. Accordingly, the sample size for each faculty was as follows: medical school $=130$ students, dentistry $=20$, pharmacology $=30$, health $=50$, nursing and midwifery $=50$, and paramedicine $=100$ students. Inclusion criteria included willingness to participate in the study and studying at the second term and above. Exclusion criteria were absence on sampling day and failure to answer all questionnaire questions.

\section{Measurement instruments}

The study tools consisted of individual data collection form and the Palsane and Sharma Study Habit Inventory (PSSHI). The individual information forms included questions about age, gender, marital status, faculty of study, academic degree, history of probation, being native or non-native, and the grade point averages (GPAs) of the previous term(s).

The PSSHI is a standard tool designed by Palsane and Sharma in India (1989) ${ }^{10}$ and its reliability is higher than that of other study habits questionnaires. ${ }^{13}$ Validity and reliability of the original version of this questionnaire have 
been confirmed in previous studies. ${ }^{10,14,15}$ Siahi and Maiyo (2015) reported the reliability coefficient of 0.88 for the PSSHI. $^{7}$ The reliability coefficient of the Persian version of this tool has also been reported as $0.88 .{ }^{10}$ In the current study, content validity analysis was used to determine the validity of the instrument. For this purpose, the questionnaire was distributed among 12 panels of experts at KUMS. They were asked to review the questionnaire in terms of fluency, clarity, and relevance. It was then modified based on their opinions. Test-retest method was used to examine the reliability of the PSSHI. In this regard, the questionnaire was distributed among 20 students, and after a 2-week interval, they were asked to answer the questionnaire. Correlation coefficient of the pre-test and posttest scores was 0.87 , which was acceptable.

PSSHI has 45 questions and measures the study habits of students in eight areas, including time management (five items), eg, "I study at a specific time of the day."; physical conditions (six items), eg, "I get disappointed by the noise around me."; learning motivation (six items), eg, "if I do not understand something, I get help from others."; reading ability (eight items), eg, "before reading the intended chapter, I read its main points."; note-taking (three items), eg, "I take notes while reading the text."; memory (four items), eg, "I read some materials without sufficient understanding."; taking tests (ten items), eg, "before responding to the test questions, I read all the questions first." and health of study (three items), eg, "if the result of the test is not good, I feel disappointed." Responses are based on a three-option Likert scale that includes: "always or most of the time", "sometimes", and "rarely or never" which are graded from two to zero, respectively. Questions 6, 9, 13, 15, 24, 26, 34, 36, 37, 41 , and 42 are scored inversely. The score range of the questionnaire is between 0 and 90, and a score of 60 and above reflects a desirable level of study habits, a score of 31-60 indicates relatively good or moderate level of study habits, and a score of 30 or below refers to an undesirable level of study habits. The score range for each of the subcategories is as follows: time management: $0-10$; physical conditions: $0-12$; learning motivation: $0-12$; reading ability: $0-16$; note-taking: $0-6$; memory: $0-8$; taking tests: 0 20, and health of study: $0-6$. The achieved score for each sub-category was computed using the three-part spectrum method. To do this, the lowest score was subtracted from the highest score and the resulting number was divided by 3 . The resulting number was the distance of three grades which indicates the desirable, relatively desirable, and undesirable levels of each sub-category.

To assess academic achievement, the GPA(s) of the previous term(s) was used, which in the Iranian educational system is from $0-20$. For this purpose, a GPA of 17 or higher was considered as "good academic achievement", 14-16.99 as "moderate educational achievement", and a GPS of less than 13.99 was considered as "poor educational achievement".

\section{Data collection method}

First, permission to conduct the study was obtained from the KUMS Deputy for Research and Technology, and was presented to the authorities of the affiliated faculties. In the next step, the list of students in each faculty was taken from the Department of Education and samples from each faculty were selected. Then, according to the classroom schedules, the selected samples were approached and after explaining the purpose of the study to them, a copy of the questionnaire was given to those who agreed to take part in the study. If any of the samples did not want to continue participating in the study, he/she was replaced by a person above or below him/her in the list. The questionnaires were collected by the researcher after completion.

\section{Data analysis}

Data were analyzed using 18th version of the Statistical Package for Social Sciences (SPSS v.18.0; SPSS Inc., Chicago, IL, USA). Descriptive and inferential statistics were used to analyze the data. At first, KolmogorovSmirnov test was used to assess the normality of the data, which showed that academic achievement of students did not have a normal distribution, but the rating of study habits had a normal distribution. Mann-Whitney $U$ test was used to compare academic achievement in terms of dual-mode qualitative variables (such as gender and marital status), and Kruskal-Wallis H test was used to compare academic achievement in terms of multi-mode qualitative variables (such as academic degree and faculty of study). Pearson correlation coefficient was used to evaluate academic achievement in terms of quantitative variables. The $t$-test was used to compare the mean of study habits in terms of dual-mode qualitative variables (gender and marital status) and ANOVA was used to compare the mean of study habits in terms of multi-mode qualitative variables (such as academic degree and faculty of study). Pearson correlation coefficient was used to investigate the 
relationship between academic achievement and study habits. $p$-values less than 0.05 were considered as significant.

\section{Ethics}

The study was approved by the Ethical Review committee of the Kermanshah University of Medical Science with code: KUMS.REC.1395.292. Objectives of the study were explained to the participants and they were assured about the confidentiality of their information and their responses. Iinformed written consent was also obtained from all participants.

\section{Results}

Of the 380 students participating in this study, $65.3 \%$ $(n=248)$ were male and $34.3 \%(n=132)$ were female. The mean age of the students was $22.26 \pm 2.9$ years. Most of the students were single $(91.1 \%, \mathrm{n}=346)$, and had no history of probation $(92.1 \%, \mathrm{n}=350)$. The majority of the students were from faculties of medicine $(34.2 \%, \mathrm{n}=130)$ and paramedicine $(26.3 \%, \mathrm{n}=100)$. Most students were studying at doctoral $(47.4 \%, \mathrm{n}=180)$ and undergraduate $(45.5 \%$, $\mathrm{n}=173$ ) levels. They were also mainly native students $(59.2 \%, \mathrm{n}=225)$, (Table 1$)$.
The mean score of students' study habits was 45.7 \pm 11.36 out of 90 . In terms of study habits, only $10 \%$ $(n=38)$ were on a desirable level and $81.3 \% \quad(n=309)$ were on a moderate level. Also, 8.7\% $(n=33)$ of them were on an undesirable level. In terms of the eight areas of study habits, the status of most students was undesirable in the areas of taking notes $(50.2 \%, \mathrm{n}=191)$ and well-being $(48 \%, \mathrm{n}=182)$, and was desirable in the area of time $(27.3 \%, n=104)$. The status of most students in the other areas was moderate (Table 2).

The mean of students' total GPA of the term(s) was considered as an indicator of academic achievement, which was $15.73 \pm 1.5$ out of 20 . The highest and lowest levels of academic achievement were respectively for the students in faculties of health and medicine with a mean and SD of $16.27 \pm 1.48$ and $15.08 \pm 1.39$ respectively, which showed a statistically significant difference $(p<0.001)$. The highest and lowest levels of academic achievement were respectively related to the $\mathrm{MSc}$ and doctoral students with a mean and SD of $16.98 \pm 1.61$ and $15.19 \pm 1.38$ respectively, which showed a statistically significant difference $(p<0.001)$. Academic achievement in students without history of probation was significantly higher than those with history of probation with a mean and SD of $15.86 \pm 1.42$

Table I Demographic variables and comparison of the academic performance and study habits based on underlying variables

\begin{tabular}{|c|c|c|c|c|c|c|}
\hline \multicolumn{2}{|l|}{ Variables } & \multirow{3}{*}{$\begin{array}{l}\text { Number (\%) } \\
132(34.7) \\
248(65.3)\end{array}$} & \multicolumn{2}{|c|}{ Academic achievement } & \multicolumn{2}{|l|}{ Study habits } \\
\hline & & & \multirow{2}{*}{$\begin{array}{l}\text { Mean(SD) } \\
16.15(1.34) \\
15.50(1.5)\end{array}$} & \multirow{2}{*}{$\begin{array}{l}\mathbf{p} \text {-value } \\
* * *<0.001\end{array}$} & \multirow{2}{*}{$\begin{array}{l}\text { Mean(SD) } \\
46.68(9.91) \\
45.18(12.05)\end{array}$} & \multirow{2}{*}{$\begin{array}{l}p \text {-value } \\
{ }^{* \dagger} \text { NS }\end{array}$} \\
\hline Gender & $\begin{array}{l}\text { Female } \\
\text { Male }\end{array}$ & & & & & \\
\hline Marital status & $\begin{array}{l}\text { Married } \\
\text { Single }\end{array}$ & $\begin{array}{l}34(8.9) \\
346(91.1)\end{array}$ & $\begin{array}{l}15.57(1.7 \mid) \\
15.74(1.48)\end{array}$ & $*^{*} *{ }^{\dagger} N S$ & $\begin{array}{l}43.61(13.38) \\
45.91(11.15)\end{array}$ & $* N S$ \\
\hline History of probation & $\begin{array}{l}\text { Yes } \\
\text { No }\end{array}$ & $\begin{array}{l}30(7.9) \\
350(92.1)\end{array}$ & $\begin{array}{l}\text { I4.20(I.67) } \\
\text { I5.86(I.42) }\end{array}$ & $* * *<0.001$ & $\begin{array}{l}40.33(13.69) \\
46.16(I 1.04)\end{array}$ & $* 0.007$ \\
\hline Place of residence & $\begin{array}{l}\text { Native } \\
\text { Non-native }\end{array}$ & $\begin{array}{l}230(60.5) \\
150(39.5)\end{array}$ & $\begin{array}{l}\text { I5.87(I.39) } \\
\text { I5.49(I.62) }\end{array}$ & $* * * 0.049$ & $\begin{array}{l}46.98(I 0.67) \\
43.58(I 2.23)\end{array}$ & $* 0.009$ \\
\hline College of Education & $\begin{array}{l}\text { Medical } \\
\text { Dental } \\
\text { Nursing and midwifery } \\
\text { Pharmacy } \\
\text { Paramedical } \\
\text { Health }\end{array}$ & $\begin{array}{l}130(34.2) \\
20(5.3) \\
50(13.2) \\
30(7.9) \\
100(26.3) \\
50(13.2)\end{array}$ & $\begin{array}{l}15.08(I .39) \\
15.87(I .38) \\
16.04(I .36) \\
15.22(I .24) \\
16.26(I .48) \\
16.27(I .48)\end{array}$ & $* * * *<0.001$ & $\begin{array}{l}45.51(10.93) \\
43.20(12.58) \\
48.66(9.63) \\
43.33(9.35) \\
44.44(I 1.66) \\
48.20(13.37)\end{array}$ & $* * N S$ \\
\hline Level of graduation & $\begin{array}{l}\text { Associate degree } \\
\mathrm{BSc} \\
\mathrm{MSc} \\
\mathrm{PhD}\end{array}$ & $\begin{array}{l}23(6.1) \\
173(45.5) \\
4(1.1) \\
180(47.4)\end{array}$ & $\begin{array}{l}16.61(1.09) \\
16.14(1.47) \\
16.98(1.61) \\
15.19(1.38)\end{array}$ & $* * * *<0.001$ & $\begin{array}{l}44.52(11.99) \\
46.44(11.69) \\
57(11.34) \\
44.89(10.87)\end{array}$ & $* * N S$ \\
\hline
\end{tabular}

Notes: ${ }^{*}$ Independent $t$-test; ${ }^{* *}$ ANOVA; ${ }^{* * *}$ Mann-Whitney $\mathrm{U}$ test; ${ }^{* * * k \cdot k}$ kruskal-Wallis $\mathrm{H}$ test; ${ }^{\dagger}$ non-significant. 
Table 2 Frequency of subcategories of students' study habits

\begin{tabular}{|l|l|l|l|}
\hline Subcategory & Undesirable, number (\%) & Relatively desirable,number (\%) & Desirable, number (\%) \\
\hline Time & $90(23.6)$ & $186(49.1)$ & $104(27.3)$ \\
Physical status & $50(13.1)$ & $269(70.9)$ & $61(16)$ \\
Ability to read & $48(12.5)$ & $309(81.4)$ & $23(6.1)$ \\
Making notes & $191(50.2)$ & $140(37)$ & $49(12.8)$ \\
Memory & $36(9.4)$ & $278(73.1)$ & $66(17.5)$ \\
Learning motivation & $61(16.1)$ & $231(60.7)$ & $88(23.2)$ \\
Taking tests & $28(7.2)$ & $306(80.6)$ & $46(12.2)$ \\
Well-being & $182(48)$ & $164(43.2)$ & $34(8.8)$ \\
\hline
\end{tabular}

and $14.20 \pm 1.67$, respectively $(p<0.001)$. Female students had better academic achievement compared to male students with a mean and SD of $16.15 \pm 1.34$ and $\pm 15.5 \pm 1.5$, respectively. This difference was statistically significant $(p<0.001)$, (Table 1).

The results showed that, students of the faculty of nursing and midwifery and the faculty of dentistry had the highest and the lowest mean of study habits with mean and SD of $48.66 \pm 9.63$ and $43.20 \pm 12.58$ respectively, which was not statistically significant. In terms of academic degree, MSc and undergraduate students had the highest and lowest average of study habits, with a mean and SD of $57 \pm 11.34$ and $44.52 \pm 11.99$ respectively, which was not statistically significant. Students without history of probation had a significantly better status of study habits compared to students with probation history $(p<0.001)$, with a mean and SD of $46.16 \pm 11.04$ and $40.33 \pm 13.69$, respectively. The results showed that the status of study habits of female students was better than that of male students respectively, with a mean and SD of $46.68 \pm 9.91$ and $45.18 \pm 12.05$ respectively, but this difference was not statistically significant. Native students had significantly better status of study habits compared to dormitory students $(p<0.001)$, with a mean and SD of $46.98 \pm 10.67$ and $43.58 \pm 12.23$, respectively.

Pearson correlation test showed a direct and significant relationship between academic achievement and study habits $(\mathrm{r}=0.235, p<0.001)$.

\section{Discussion}

In our study, the status of study habits of most students was at moderate level and only one tenth of the students were at the desirable level. Mendezabal (2013), in a study that investigated the study habits of 239 Filipino students, reported their study habits to be at moderate level, which indicated insufficient and ineffective study skills. ${ }^{12}$ On the other hand, the results of a study conducted on librarian students in Iran indicated the general level of students' study habits to be 60.5 out of $100 .^{5}$ Although the level of study habits in this study was moderate, this level was higher in our study, which may be due to the differences in the nature of medical sciences and librarian academic programs. In another study that Garner (2013) conducted on 59 undergraduate chemistry students in West Indies, the level of study habits was at desirable level in $59.2 \%$ of the students, and this level was poor in the rest. ${ }^{16}$ The difference between the results of this study and our study could be due to the low numbers of participants in Garner's study and the differences in the tool used to measure study habits, because the tool used in Garner's study classified study habits into two good and poor level and eliminated the intermediate level, which might have reduced the accuracy of data and comparative capability of the study.

In our study, in terms of eight areas of study habits, the status of study habits in most students was undesirable in the areas of taking notes and well-being, and was desirable in the area of time. The status of study habits in most students in the other areas was at moderate level. Regarding the different areas of study habits, the results of studies are varied. In this regard, the result of a study conducted on 150 nursing students in Iran showed that most of the students' problems were related to taking notes, reading ability, time management, well-being, memory, motivation, learning, physical condition, and taking tests. ${ }^{22}$ In some studies, time management has been described as one of the major problems for medical students. ${ }^{17,18}$ Mendezabal (2013) also referred to problems such as ineffective time management, lack of planning and concentration, poor study skills, and inadequate examination techniques. ${ }^{12}$ The differences in the 
areas of study habits can be attributed to the individual differences between the samples and their previous educational systems.

In our study, the students in the faculties of nursing and midwifery and dentistry had the highest and the lowest mean study habits, respectively. This difference was not statistically significant. Despite the fact that this variable has not been discussed in most studies, this finding reflects the relatively similar level of study habits in the students of various medical sciences academic programs.

In our study, there was no significant difference between different educational levels in terms of the mean study habits. In other words, the level of study habits in different educational levels was equal. Our results are in line with the study of Fereydoonimoghadam and Cheraghian. ${ }^{19}$ According to the authors of the present article, every student of medical sciences, regardless of what degree level he/she is studying at, should be aware of study skills and habits and how to apply them.

In the present study, students with no history of probation had significantly better status of study habits compared to the students with a history of probation. Despite the fact that many studies have not addressed this variable, Rezaie and Nourian in their studies, have pointed to a meaningful relationship between probation and poorer academic performance, and have considered study habits as an important factor influencing these variables. ${ }^{10,11}$ In this regard, Khan (2016) described poor study habits as the most important reason for students' academic failure. ${ }^{20}$ In our view, students with poor academic performance, by utilizing the proper skills and study habits, can improve their academic performance and thereby prevent the emergence of educational problems, such as dropping academic unit/credits and probability of probation.

In our study, the status of study habits in male and female students did not differ from each other significantly, in other words, in terms of skills and study habits, male and female students were at the same level. Oli (2018), Hashemian (2014), and Torabi (2014) also did not find any significant difference between the students' gender and study habits, ${ }^{5,21,22}$ which can be due to the same educational environment for male and female students. In our view, every student, whether male or female, should be aware of study skills and habits and use them.

We found that native students had significantly better study habits compared to dormitory students. However, some studies did not report statistical significance between study habits and place of residence. ${ }^{14}$ In our opinion, the conditions of place of residence, especially the place of study, play an important role in the study habits of students. Failure to observe the necessary standards in dormitories and the lack of suitable environment and conditions can have a negative effect on students' performance.

We found a positive and significant correlation between academic performance and study habits, which is consistent with the results of studies by Fereydoonimoghadam and Cheraghian (2009), Alimohamadi (2018), and Rabia (2017). ${ }^{13,19,23}$ However, Lawrence (2014) and Torabi (2014) did not find any significant statistical relationship between study habits and academic performance. ${ }^{1,21}$ We believe that the utilization of study skills and habits can play a positive role in improving academic performance of students. Academic achievement and achieving educational goals require the existence of several factors, the most important of which is the study habits of individuals, ${ }^{13}$ since the use of various and effective methods of study improves academic performance of students. Strengthening each of the eight areas of study skills can help to improve the academic performance of students, thus it is necessary to pay attention to these areas. Since academic performance is considered as a predictor of success in a person's career, it is important to pay attention to this issue and apply appropriate strategies to improve the study habits of students. Meanwhile, because of the high sensitivity of future professions in medical students, and the need for comprehensive learning of the curriculum, paying attention to the status of study habits and its promotion is critically important.

There are some limitations to this study. First, this was a cross-sectional study and according to the nature of cross-sectional studies, it is not possible to determine the causal relationships between study variables. Another limitation in this study was related to the data collection method, which was self-reporting. Despite reassuring the samples about the confidentiality of their responses, this approach might have had an impact on the accuracy of our results.

\section{Conclusion}

In our study, the academic performance and study habits of most students were at moderate level, which is not satisfactory considering the nature and importance of medical sciences. There was a significant relationship between study habits and academic achievement of students. Considering the important role of study habits in academic achievement and future careers of students, and since the majority of study habits can be taught and corrected, it is recommended that students' study habits should be 
measured at the time of their entry to university, and during their studies, so they can receive training in order to learn or modify study habits. The present study was conducted on students of medical sciences. It is recommended that similar studies are conducted on students of other scientific fields. Conducting qualitative studies to examine the factors affecting students' study skills and habits may also be beneficial.

\section{Acknowledgments}

This work was supported by the deputy of research and technology of KUMS (grant number 95306)]. The authors would like to thank the president and co-workers of deputy of research and technology of KUMS, and all the students who patiently participated in our study. We also extend our thanks to the clinical research development center of Imam Reza Hospital affiliated to KUMS for their kind help.

\section{Disclosure}

The authors report no conflicts of interest in this work.

\section{References}

1. Lawrence A. Relationship between study habits and academic achievement of higher secondary school students. Online Submission. 2014;4 (6): $143-145$

2. Odiri OE. Relationship of study habits with mathematics achievement. J Educ Pract. 2015;6(10):168-170.

3. Arora R. Academic achievement of adolescents in relation to study habits. Int J Indian Psychol. 2016;3(9):48-54.

4. Kamoru U, Ramon OG. Influence of self-concept, study habit and gender on attitude and achievement of secondary school students in mathematics. J Leadersh Instruction. 2017;16(1):49-52.

5. Hashemian M, Hashemian A. Investigating study habits of library and information sciences students of Isfahan University and Isfahan University of medical sciences. Iran J Med Educ. 2014;14(9):751-757.

6. Ebele UF, Olofu PA. Study habit and its impact on secondary school students' academic performance in biology in the Federal Capital Territory, Abuja. Educ Res Rev. 2017;12(10):583-588. doi:10.5897/ERR

7. Siahi EA, Maiyo JK. Study of the relationship between study habits and academic achievement of students: a case of spicer higher secondary school, India. Int J Educ Administration Policy Stud. 2015;7 (7):134-141. doi:10.5897/IJEAPS2015.0404
8. Kyauta AMA, Shariff YA, Garba HS. The role of guidance and counseling service on academic performance among students of umar suleiman college of education, Gashua, Yobe State, Nigeria. KIU J Humanities. 2017;2(2):59-66.

9. Eva KW, Bordage G, Campbell C. Towards a program of assessment for health professionals: from training into practice. Adv Health Sci Educ. 2016;21(4):897-913. doi:10.1007/s10459-015-9653-6

10. Rezaie Looyeh H, Seyed Fazelpour SF, Reza Masoule S, Chehrzad MM, Kazem Nejad Leili E. The relationship between the study habits and the academic performance of medical sciences students. $J$ Holistic Nurs Midwifery. 2017;27(2):65-73. doi:10.18869/acadpub. hnmj.27.2.65

11. Nourian A, Shah Mohammadi F, Mousavi Nasab SN, Nourian A. Study skills and habits of the students in Tehran Islamic Azad University of medical sciences in the academic year 2008-2009. Strides Dev Med Educ. 2011;7(2):104-111.

12. Mendezabal MJN. Study habits and attitudes: the road to academic success. Open Sci Repository. 2013; 70081928.

13. Alimohamadi N, Dehghani M, Saeide w, et al. Relation study between study habit and academic performance of nursing students in Hamadan. Pajouhan Sci J. 2018;16(3):29-38. doi:10.21859/ psj.16.3.29

14. Alavi H, Lesani M, Study Habits MJ. Achievement: a comparison of medical and paramedical students. Int J Indian Psychol. 2017;4 (2):70-75

15. Sreelekha V, Indla Y, Reddy R, et al. Study habits and academic performance of first year MBBS students. Int J Med Sci Public Health. 2016;5(9):1831-1834. doi:10.5455/ijmsph.

16. Garner-O'Neale LD, Harrison S. An investigation of the learning styles and study habits of chemistry undergraduates in Barbados and their effect as predictors of academic achievement in chemical group theory. J Educ Soc Res. 2013;3(2):107-122.

17. Nolan MF. A method to assist students with effective study habits and test-taking strategies. Med Sci Educ. 2015;25(1):61-68. doi:10.1007/s40670-014-0091-5

18. Nwosu KC, Okoyoe CC, Onah UH. An interpretive descriptive study of factors affecting academic achievement of underachieving student teachers in Nigeria. J At-Risk Issues. 2018;21(2):20-29.

19. Fereydoonimoghadam M, Cheraghian B. Study habits and its relation to academic performance in abadans nursing students. Strides Dev Med Educ. 2009;6(1):21-28.

20. Khan ZN. Factors effecting on study habits. World $J$ Educ Res. 2016;3(1):145-150. doi:10.22158/wjer.v3n1p145

21. Torabi M, Haghani J, Mousavi I. Reviewing the dental students' skills and habits in Kerman University of Medical Sciences, Iran. Strides Dev Med Educ. 2014;11(2):244-250.

22. Oli A, Hossain MA, Rana MS. Role of self-esteem and study habit on academic achievement of university students. Bangladesh J Psychol. 2018;21:81-92.

23. Rabia M, Mubarak N, Tallat H, Nasir W. A study on study habits and academic performance of students. Int J Asian Social Sci. 2017;7 (10):891-897. doi:10.18488/journal.1

\section{Publish your work in this journal}

Advances in Medical Education and Practice is an international, peerreviewed, open access journal that aims to present and publish research on Medical Education covering medical, dental, nursing and allied health care professional education. The journal covers undergraduate education, postgraduate training and continuing medical education including emerging trends and innovative models linking education, research, and health care services. The manuscript management system is completely online and includes a very quick and fair peer-review system. Visit http://www.dovepress.com/testimonials.php to read real quotes from published authors. 